\title{
Can Ethical Organizational Character Be Stimulated and Enabled?: "Upbuilding" Dialog As Crisis Management Method
}

\author{
Richard P. Nielsen \\ Ron Dufresne
}

"Life can only be understood backwards, but it must be lived forwards ... Dialectically the position is this: the principle of association, by strengthening the individual, enervates him .... It is only after an ethical outlook, in the face of the whole world ... that there is really joining together." Soren Kierkegaard

Richard P. Nielsen is Professor, Organization Studies Department, Carroll School of Management, Boston College. He works as a participatory action researcher, educator, and consultant in the areas of ethics intervention and corruption reform methods. He was elected to the Board of Directors and will be serving as President and Program Chair of the Society For Business Ethics. He is currently serving as Senior Editor for Ethics and Social Responsibility related articles of Organization Studies, the journal of the European Group for Organizational Studies. His publications include The Politics of Ethics: Methods For Acting, Learning, and Sometimes Fighting, With Others In Addressing Ethics Problems In Organizational Life. Oxford University Press, Ruffin Series in Business Ethics. In addition, he has published more than 75 articles in journals. He has consulted and done executive training work in Asia, Europe. Latin America and North America.

Ronald L. Dufresne is a Ph.D. candidate in the Organization Studies Department of the Carroll School of Management at Boston College. His broad research interest entails examining the positive aspects of organizations and organizational life. Specifically, he is interested in studying individual and organizational learning from crises, morality in organizations, dignity in dirty work, and action learning. Ron's research has appeared in several outlets, including Human Relations, Group and Organization Management, Management Learning, and the forthcoming edited volume, Positive psychology in business ethics and corporate social responsibility (Information Age).
ABSTRACT. Crisis management can be simultaneously a content specific problem solving process and an opportunity for stimulating and enabling an organization's ethical tradition. Crisis can be an opportunity for ethical organizational development. Kierkegaardian "upbuilding” dialog method builds from within the internal ethical tradition of an organization to respond to crises while simultaneously adapting and protecting the organization's tradition. The crisis itself may not be a directly ethical crisis, but the method of responding to the crisis is built upon the ethical foundations of an organization's tradition. A limitation of this method is that it may be less applicable to organizations with questionably ethical traditions. The concept of "upbuilding" dialog is derived from Kierkegaard, but here is applied to organizational crisis management. The method is illustrated and discussed in the context of a wrongful death crisis of the Dana- Farber Cancer Institute, a nonprofit organization, and an economic survival crisis at Ben and Jerry's, a business organization.

KEY WORDS: Ethics, organizational character, crisis, Kierkegaard

\section{Introduction}

Crises can be both serious threats as well as opportunities for development of individual character and perhaps also organizational character. This paper considers how the problem of organizational crisis management might be appropriately addressed with a dialogic, ethics method, that may, in turn, stimulate organizational character. The process method includes, gives voice to, and may dialectically stimulate an organization's ethical tradition and character while addressing the problem of crisis management. 
The type of dialogic process, "upbuilding" dialog, is derived from Kierkegaard, but here is applied to organizational crisis management. There are some Aristotelian roots to Kierkegaard's developmental philosophy that are discussed below. With the "upbuilding" method, when an organization can openly and respectfully approach other stakeholders in a crisis, can frame the crisis as being potentially harmful to the organization's ethical tradition, it can begin to contain the crisis and simultaneously stimulate and enable the organization's ethical tradition. By proposing and adopting solutions that are informed by the organization's ethical tradition but that also question that tradition, the organization can begin to recover from the crisis as well as learn from, change, and develop in light of the lessons presented by the crisis.

For Aristotle (The Nicomachean Ethics, Books One and Ten), the choices we make, particularly the choices we make in pressured type situations such as crises, are key to individual character development. Aristotle further suggests that "for while it is desirable to secure what is good in the case of an individual, to do so in the case of a people or a state is something fine and more sublime (Aristotle, 1955, p. 64)." Might the same be true for the common good of organizations, their organizational stakeholder communities, and perhaps even organizational characters as shaped by the process choices they make in crisis situations?

Feldman (2002) in his Memory as a Moral Decision: The Role of Ethics in Organizational Culture links the concepts of ethics and organizational cultures and traditions. Feldman (2002, p. ix), explains, "The theory of moral tradition is designed to investigate the historical and cultural context of moral commitment .... I apply this framework to theories of organizational culture to investigate their moral assumptions and moral implications, that is, to explicate and understand the moral life they imply."

According to the Oxford English Dictionary (1971, p. 1178), the English word "crisis" comes from the Greek word "Krisis." The OED's definition of crisis is "A vitally important or decisive stage in the progress of anything; a turning point; also, a state of affairs in which a decisive change for better or worse is imminent; now applied especially in times of difficulty, and suspense in politics or commerce."
According to the social scientist and crisis management scholar, Shrivastava (1993, p. 25), "Crises are situations that threaten the survival of the system. They cause restructuring of the system ... crisis refers to disruptive situations characterized by urgency of decision, large impacts, and system restructuring."

Much of the literature on crisis management is about externally and/or internally induced, largescale catastrophic events such as global market or institutional field changes, natural disasters, radical technological changes, or accidents such as those at the Chernobyl nuclear power plant or the Bhopal chemical plant (Audia et al., 2000; Deephouse, 1996; DiMaggfio and Powell, 1983; Fiol, 2002; Haverman, 1992; Hill and Rothaemel, 2003; Kostova and Zaheer, 1999; Mitroff et al., 1988; Oliver, 1991; Pearson and Clair, 1998; Shrivastava, 1993;). The field also recognizes that an event does not have to be this large-scale to qualify as a "crisis."

The organizational crisis and change literature also distinguishes two distinct types and/or approaches to crisis management: reactive and proactive. Proactive steps can involve developing processes for anticipating crisis threats and opportunities, methods and processes for dealing with anticipated crises, and even creating crises in order to stimulate change and development opportunities (Argyris et al., 1985; Collins and Porras, 1994; Lewin, 1951; Nielsen, 2003; Senge, 1990).

The reactive nature of crisis management reflects what organizations actually do and methods and processes organizations use and go through in the face of a realized crisis (Czarniawska, 1997; Fiol, 2002; Hill and Rothaermel, 2003; Nielsen, 2003). This reactive type of crisis management is the focus of Kierkegaardian "upbuilding" method that builds from within an internal ethical tradition to respond to crises while simultaneously adapting and protecting the tradition. This method has also been applied to directly ethics issues (Nielsen, 1996a).

Reactive crisis management methods are concerned with such things as how to contain the crisis, recover from the crisis, and learn and/or transform from the crisis experience (Mitroff et al., 1988). For example and in an ethics context, Pearson et al., (1997) consider the reactive crisis management steps taken by Johnson and Johnson in the wake of the Tylenol poisoning as a method for containing, recovering, and learning from the crisis. In that case, 
an outsider was poisoning Tylenol packages within retail stores. Johnson and Johnson withdrew all the Tylenol packages from the market at great financial cost. They found that a critical cause of Johnson and Johnson's success in this crisis management case was the fact that the company was guided in its reaction to the crisis by its traditional values concerning the company's priorities, employees, and other stakeholders. Unfortunately, in a more recent Johnson and Johnson case, it was found that company insiders suppressed for over twenty years information about the liver damaging side-effects of its Tylenol drug (Bates and Hall, 1994; Grady, 1997; Tennant, 2004). It may be that more people have died from the liver damage than the cyanide poisoning. Both organizations and individuals can sometimes act both ethically and unethically and use ethics methods for both ethical and not so ethical reasons.

The purpose of this article is to introduce, evaluate, and advocate for appropriate circumstances, the "upbuilding" dialog method as an organizational crisis management method and as a method for stimulating and enabling an organization's ethical tradition. Limitations of the method are also considered. Examples of other types of dialogic processes that have been used explicitly to help solve organizational crisis problems are action-science dialog (Argyris and Schon, 1988), action-learning dialog (Torbert, 1987), Socratic dialog (Nielsen, 1989), and Woolman dialog (Nielsen, 1993).

This article is developed as follows. First, the Kierkegaardian origins of the methods are discussed. Second, the "upbuilding" dialog method used in the Dana-Farber and Ben and Jerry's crisis management cases are presented. Third, strengths and limitations of the method for ethical crisis management are discussed.

Two cases, a nonprofit organization case and a business organization case, are presented here, the Dana-Farber and Ben and Jerry's cases. These cases were selected to demonstrate that the method has and can work in very different political-economic sectors such as nonprofit institution and business institution sectors. Other organizations such as Cadburys (Smith et al., 1990; Nielsen, 1996b), Scandinavian Airlines (Carlzon, 1987), Polaroid (Ewing, 1989), and Tom's of Maine (Chappel, 1993) have also successfully used variations of "upbuilding" dialog. There are many different types of strong, ethical organization traditions and many different types of problematical environments. The key to the "upbuilding" dialog method is not the particular organization tradition or the particular problematical environmental situation. Instead, the key to the method is building upon ethical foundations of an internal tradition to manage crises while also adapting and protecting the ethical tradition within a problematical environment.

\section{Kierkegaard "upbuilding" method}

The "upbuilding" ethics based approach to crisis management considered in our paper is an adaptation of Kierkegaard's "upbuilding" method. The English language word "upbuilding" is Steere's (1938) translation of the Danish word, "opbuggelig" that Kierkegaard used. Our interpretation and adaptation of the Kierkegaard method is based primarily on personal conversations with the late $\mathrm{Ki}$ erkegaard scholar, Douglas Steere, our reading of the English language translations of the original Kierkegaard works, as well as our interpretations of the published analyses of Kierkegaard's work by Bernstein (1971), Fleischacker (1994), Kearney (1988), Lowrie (1942), and Steere (1938).

Originally and more specifically, Kierkegaard was concerned with Danish social, religious, and individual ethical development that he considered threatened by external, problematical German and French military, political, and intellectual environmental influences. Kierkegaard was also concerned with the need to simultaneously reform, adapt and protect the Danish social and religious ethical tradition in this context of a threatening environment. Kierkegaard did not specifically consider problems of organizational crisis management or organizational ethics.

There are four elements in Kierkegaard's philosophy of "upbuilding" that correspond to the four processes in "upbuilding" dialog (Bernstein, 1971; Fleischacker, 1994; Kearney, 1988, Kierkegaard, 1845, 1846a, b, 1847b; Lowrie, 1942; Steere, 1938, 1949).

(1) Friendly, respectful affect: Kierkegaard was concerned with ethical process. For Kierkegaard, an important part of ethical process was friendly, respectful, and even loving expression while in 
actual or potential conflict with others. This does not mean that one cannot or does not feel angry, the concern is with appropriate expression. Kierkegaard (1946, p. 45) has not suggested that it is necessary or practical to always "admire the neighbor - but one must love him." Kierkegaard's position is similar to the familiar, but nonetheless difficult, ethical ideal, "Hate the sin, but love the person." Kierkegaard did not suggest that we understate our ethical concerns in order to avoid conflict. Rather, we should express our concern both fully and in a friendly, respectful manner.

Kierkegaard (1847b, 1948, pp. 183-184) explains his friendly, respectful approach: "a man can, to be sure, have an extremely different, yes, have a precisely opposite opinion from our own, and one can nevertheless deal earnestly with him if one assumes that finally there may be a point of agreement, a unity in some universal human sense, call it what you will. But if he is mad (angry), then one cannot deal with him. One can dispute with a man, dispute to the farthest limit, as long as one assumes, that in the end there is a point in common, an agreement in some universal human sense: in ... respect."

By extension, Kierkegaard also was opposed to adversarial "us versus. them" group divisions in society. Kierkegaard (1847b, 1948, p. 206) explicitly criticized adversarial divisions among socioeconomic classes, the professions, types and levels of intelligence. For Kierkegaard, it is our common ethical concern which has the potential for uniting across such divisions.

(2) Framing the issue as a problematical environment threatening ethical action and ethical tradition: At the time Kierkegaard was writing about his "Upbuilding" approach in the 1840s, Europe was experiencing both progress and very powerful and often destructive changes that accompanied the growth of industrialization and the spread of ideas, at times distorted ideas, from the French Revolution. Napoleon's massive, primarily volunteer, revolutionary armies had overthrown several monarchist governments and left much devastation in their wake. The Napoleonic, anti-monarchist movement had only been defeated, perhaps temporarily, by the primarily conscripted, combined monarchist military forces some 25 years before. Concurrently, mass production and industry was often accompanied by rapidly increasing urbanization, industrial conflict, public health problems, and serious breakdowns in local community.

From the perspective of the small, relatively peaceful country of Denmark, large parts of Europe appeared to be buffeted by waves of uncontrollable, destructive social forces. For many, these external forces appeared to be infected with destructive, "crowd" (Kierkegaard's word) mentalities that were unable to discern well among the positive and negative aspects of ongoing mass social changes.

Kierkegaard compared the problem of doing ethics, which he considered an essentially local activity, with trying to travel around Denmark with the help of a small map of Europe on which Denmark would show no larger than a pin point (Kierkegaard, 1846a, p. 277) Similarly, Kierkegaard was concerned with unthinking conformity to mass, popular opinion trends (Kierkegaard, 1846b, 1962, pp. 64-65). Kierkegaard was critical of those who sought what he considered vicarious power through identification with mass movements as a substitute for local responsibility and local action.

(3) The solution process of "upbuilding" dialog by individuals from within a tradition: Kierkegaard was concerned with doing ethics, not just understanding ethics. Kierkegaard recognized that ethics was an interactive and continuing action and learning process, that one learns through action, and that learning informs action. For Kierkegaard (1846a, 1966, p. 143), "The ethical is not merely a knowing; it is also a doing that is related to a knowing, and a doing such that the repetition may in more than one way become more difficult than the first doing."

Key to ethical doing is dialogic method. Kierkegaard explains that when we participate in dialog with others about ethical issues, in addition to learning about ethics we are also acting ethically. It is particularly necessary to engage in dialog when the circumstances are difficult. For Kierkegaard, participating in the process of dialog is an ethical and even a courageous act as well as a learning process. By participating in the talk, we hold open the possibility of change, including change that may not be comfortable and may even be threatening.

Further, ethical dialog and ethical doing are not abstract activities, but need to be grounded in one's own concrete, local, real world, tradition (Kierkegaard, 1846a, 1968, p. 128). Kierkegaard's biographer, Lowrie $(1942$, p. 30, 90) observed that what 
exerted a prodigious influence on Kierkegaard was that "... he had an unusually vivid feeling of solidarity with the family, the clan, the race ... He was not opposed to change as such but contended against the effort to impose upon Denmark the abstract theories of the French Revolution, without taking into account the character ... the history of the nation and the institutions which had grown up in conformity with the genius of the people. The modern development of the Scandinavian nations ... with institutions peculiar to the people and appropriate to their situation, has amply justified S.K.'s contention."

More recently Fleishacker (1994, p. 78) similarly explains Kierkegaard's "upbuilding" approach as follows" "I acquire an adequate sense of my possibilities for action only when I accept the fact that my place in the world is given by my emotional and historical circumstances ... these various and conflicting requirements can be met by trusting a particular narrative that gives me my place in the world rather than allowing me to imagine I have created that place."

For Kierkegaard, embedded local, ethical wisdom does not have to be overwhelmed by waves of crowd phenomena. Just as embedded local wisdom can be positively and negatively influenced by macro social waves, so also can embedded local wisdom inform more macro social waves. Such mutual informing proceeds in mutual "talk," listening, and questioning.

(4) Ethically transformed association: For Kierkegaard, "upbuilding" method holds open the possibility for ethically imagined and transformed association. Kierkegaard refers to a "poetics" of ethics where potentialities and what ought to be can be imagined in action and made incarnate.

Kierkegaard (1846b, 1962, p. 79) explains such a transformation dialectically: "Dialectically the position is this: the principle of association, by strengthening the individual, enervates him; it strengthens numerically, but ethically that is a weakening. It is only after ... an ethical outlook, in face of the whole world, that there can be any suggestion of really joining together."

That is, if one allows oneself to be absorbed with a crowd environment, it is possible to become stronger in the sense that one is allied with a very large group beyond the local community. However, identification with macro social movements can interfere with ethical responsibility, ability and freedom at the local level. For Kierkegaard, ethics starts with local, within a tradition responsibility and action.

For example, if individuals and groups such as workers and manages consider themselves to be enemies at the national level, that can make it difficult to do cooperative, ethical problem solving at the local organizational level. For Kierkegaard, such a loss of local ethical responsibility is an ethical weakening. However, if we can "upbuild" from within our local organization tradition of cooperative, participative decision making and technological change "in the face of the whole world," then ethical problems can be solved and local association can be transformed and deepened.

\section{The Dana-Farber cancer institute case}

Following are: (a) a description of the Dana-Farber tradition and the particular problematical crisis situation; (b) a description of the method used to help give the Dana-Farber tradition a voice in the problem solving process; and, (c) a discussion of the four "upbuilding" dialog steps taken in the problem solving change process.

\section{The Dana-Farber Crisis Situation and Tradition}

The information concerning the Dana-Farber case come from extensive, investigative articles published in The Boston Globe, internal histories of the Institute, and three key interviews with a high level medical doctor-administrator, a high level non-medical administrator, and a nursing supervisor who all prefer to remain anonymous (Knox, 1995a-f; Knox and Blanton, 1995; Kong, 1995a, b; Pfeiffer, 1999).

The Dana-Farber Cancer Institute and its tradition has their roots in the late-1940s work of the pathologist Sidney Farber. In 1947, Dr. Farber was the first to succeed with a drug therapy treatment of cancer, resulting in temporary remission in over half of his juvenile patients. Over the years, Dana-Farber contributed to major advances in adult and pediatric oncology in many varieties of cancers. It was a point of the Dana-Farber Institute that these advances should not and did not come at the expense of the cancer victims as guinea pigs. Dr. Farber instituted 
the then-revolutionary concept of "total care," which established a team of medical professionals who collectively conducted very advanced and aggressive cancer research and attended to the needs of the patient and their families, including clinical care, nutrition, social work, and psychological counseling. In sum, the tradition at Dana-Farber was what the Institute called "compassionate care through research."

In November of 1994 there was a crisis. DanaFarber was conducting an experimental treatment of breast cancer that had metastasized into other parts of patients' bodies. The risky treatment, which consisted of very high-dose chemotherapy and bone marrow stem cell transplants, had been shown to improve life expectancy almost threefold. The treatments involved five women who applied for and were accepted into the program, and involved highly toxic drug dosages. A research fellow miscalculated the dosages for two of the women, resulting in the two women receiving four times the intended drug dosage. The miscalculation, which slipped past the notice of several nurses and pharmacists, led to the death of one of the women, and permanent heart damage in the other woman. Furthermore, in the case of the woman who died as a result of the overdose, during the two weeks between the overdose and her death, none of the staff recognized her deterioration as the effects of the deadly doses.

As a result of these errors, numerous inquiries were mounted by internal and external bodies to investigate the causes of the mistakes. The fallout of this crisis at Dana-Farber was far-reaching. The Institute's bond rating was lowered, casting a cloud over its plan to construct a new research facility. The failure of the quality assurance program at DanaFarber became the subject of just the second joint investigation ever mounted by Massachusetts state agencies regulating hospitals, physicians, nurses, and pharmacists. The Institute and the research fellow faced multi-million dollar malpractice and wrongful death suits filed by the families of the deceased and injured women. An external panel downgraded Dana-Farber's accreditation from "full" to "conditional" pending the results of the investigations; this could have resulted in the Institute losing funding from Medicare and Medicaid. The case raised questions concerning the Institute's commitment to caring for its patients as humans, rather than as means (guinea pigs) to conduct prestigious research or gain lucrative research grants.

\section{'Upbuilding' dialog at the Dana-Farber cancer institute}

Following is a description of how the four 'upbuilding' dialog steps of the method were used in the Dana-Farber Cancer Institute crisis management situation.

(1) Approach others in a friendly, open and respectful manner. The Institute held empathetic respect as one of its core values, stating, "We endeavor to treat patients, their families and colleagues as we ourselves would wish to be treated." This empathetic respect served as a core motivation for the work Dana-Farber was doing to find cures and treatments for cancers. Theirs was a task of both caring for patients and aggressively looking for innovations to save human lives. As Walsh, the President of the Institute, pointed out, "We work so hard on every patient who comes in here to fight with them for their lives." Another way Dana-Farber reinforced this tradition of empathetic respect was in its hiring decisions. The Physician-in-Chief said, "When we interview young doctors, we inquire about their humanity. It's very important for the doctors who come here to be real people."

In the face of the crisis following the overdose, the administrators at Dana-Farber continued this open, respectful, friendly approach with the public and the press. The President and Physician-in-Chief were very open and vowed to share the findings of their investigations with the public. Over the following several months they exposed the flaws in the Institute's quality assurance program, training of young doctors and nurses, procedures for handling high-risk treatments, and even, through their own eventual resignations, the imbalance between research and clinical care. As leaders of a nonprofit organization that relied extensively on donations and public support, these two administrators recognized that throughout the crisis they had to maintain their respectful, open and friendly approach to others.

(2) Frame the problem as a conflict between potentially destructive environment and our internal tradition. Throughout the crisis at Dana-Farber, encompassing the overdosing of two cancer patients 
and the tumultuous year that followed, the hospital's leadership openly and aggressively investigated the causes of the crisis. Their introspection was open with the public and the Institute accepted responsibility for errors and took immediate steps to remediate those errors. This public introspection had as its foundation the Institute's internal tradition of "compassionate care through research," but recognized the potentially destructive effects of the environment leading up to the crisis.

Throughout this public introspection, the Institute's President and Physician-in-Chief recognized several facets of the problematic environment. One factor was an underlying tension between the requirements of obtaining outside research funding and compassionate patient care at the Institute. Sometimes, the compassionate "total care" of a patient was difficult to balance with the aggressive science required to make quantum leaps in the treatment or cure of cancer. This balance was further strained by the climate of the health care field at the time, when Dana-Farber, as a small specialty hospital relying greatly on outside research funding, was faced with declining patient revenues and large-scale hospital mergers. Furthermore, a degree of this underlying tension was introduced by the fact that Dana-Farber's top leadership before the crisis consisted of research scientists rather than physicians with hospital management experience. These tensions eventually resulted in the resignation and replacement of the President and Physician-in-Chief with more patient-oriented physicians.

Another way the Institute's leadership framed the crisis was that the environment was in conflict with the tradition of "compassionate care through research" was the degree of uncertainty that surrounded this type of cutting-edge research. The drug dosage plans, or protocols, could be confusing, and oftentimes the level of toxicity of the drugs, even if administered correctly, would exceed mainstream safety levels. This meant that for every drug order, everyone in the chain of action, including the prescribing doctor, the transcribing nurse, the pharmacist, and the administering nurse, had to check the order against the potentially confusing protocol. This problematic environment was addressed by the State Medical Board two years prior to the crisis at Dana-Farber when, after reports from hospitals around the state of overdoses of different chemotherapy drugs, the Board reminded hospitals of the dangers of high-dose chemotherapy.

The result of the problematic environment was a loss of focus on the internal tradition of "compassionate care through research." Doctors became more interested in their research than in attending to the needs of their patients or developing junior staff members. The quality control measures, which should have been evaluated at least annually, had not been reviewed in almost two-and-a-half years. All of these factors played a role in making it possible for the fatal quadruple dose of chemotherapy to be administered repeatedly and for no one on the staff to question the causes of the patient's rapidly decreasing state of health.

(3) Consider alternative solutions in context of ethical tradition and adaptation of tradition in context of alternative solutions. The dialog surrounding how to manage the crisis at Dana-Farber was a very public one. After The Boston Globe broke the story, there were articles written almost daily about the crisis and the steps Dana-Farber was taking to manage the crisis. The senior managers at DanaFarber committed themselves to making all investigatory results public and to be very open with the public about the problems the Institute had encountered. Some of the initial steps the top managers at Dana-Farber took included suspending the two doctors who had direct responsibility for the patient and the three pharmacists who dispensed the overdoses from all patient-care activities throughout the investigation. The Institute also suspended research with the specific drug that had caused the fatality, but still maintained its other clinical research programs. Walsh, the Institute President, said "This is one incident .... I wouldn't like that to indict a whole program. As tragic as this is, we believe it is essential to pursue research against cancer." The leaders at Dana-Farber showed their interest in adopting solutions (e.g., suspending some research, changing internal procedures, new appointments, etc.) that questioned the internal tradition while also questioning the solutions (e.g., not suspending all research or not separating research from patient care) in the context of the internal tradition.

Other steps the administrators took to create potential solutions were to make strides in its quality management program. They upgraded the Institute's pharmaceutical computer system to signal pharma- 
cists when a physician ordered an unsafe level of chemotherapy. The Institute spent over one million dollars retraining the staff on high-risk treatment protocols and expanding its family resource center. The administrators also instituted more oversight of the junior doctors and fellows by requiring senior doctors to sign off on all high-risk chemotherapy dosages. All of these potential solutions questioned the espoused internal tradition of compassionate care through research as well as the more recent de facto tradition of prioritized pursuit of aggressive cancer research.

(4) Adopting solutions that are informed by our tradition and adapting our tradition. A traditioninformed solution was adopted at Dana-Farber and the internal tradition was adapted. This solution consisted of the structural and procedural changes outlined above, as well as the reassignment of the research-oriented top management team and replacing them with more patient-oriented physicians. The result was the adoption of solutions that refocused the Institute on the "total care" of the cancer patient. In this cae, the internal tradition was adapted by re-grounding the Institute in its original tradition of "compassionate care through research." After the environment led the Institute to forgo some degree of its compassionate care, implicitly rewarding scientists for aggressive research rather than empathetic clinical care, the steps the administrators at Dana-Farber took to manage the crisis recalled the balance of patient care and effective research. All staff members, including senior physicians, interns, nurses, and pharmacists were to be members of a team of care providers while still pursuing treatments and potential cures of cancer.

\section{The Ben and Jerry's case}

\section{The Ben and Jerry's tradition and environmental situation}

Since it founding in 1978 by two friends named Ben Cohen and Jerry Greenfield, the Ben \& Jerry's tradition has been one of social responsibility, ethical employee relations, and progressiveness. This tradition has endured despite encountering many problematic environments during the company's growth from a store in a renovated gas station to a multimil- lion dollar corporation with an extensive international distribution system (Cohen et al., 1997; Mirvis, 1999; Mirvis et al., 2003; Lager and Loger, 1995). It is not clear how the tradition has been affected since its recent sale to the multinational company, Unilever. The case referred to in this paper covers the period before the sale. Some environmental forces such as corporate globalization may be very difficult if not impossible for relatively small family or closely held businesses to simultaneously maintain and adapt their internal traditions to. This might be an interesting case to look at again in ten years.

Much of the tradition at Ben and Jerry's was expressed in the concept of "linked prosperity," through which the company saw the possibility that "as the company grew and prospered, the benefits would accrue not just to the shareholders, but also to the employees and the community. Each constituency's interests were intertwined with the others (Lager and Loger, 1995, p. 126)." This tradition led Ben and Jerry's to such decisions as donating $7.5 \%$ of all pre-tax profits to charity, buying brownies for one of its flavors from a non-profit baker that employees and trains the homeless in Yonkers, New York, and instituting a salary structure that restricted the amount the best-paid executive could earn to no more than five times the wages of the lowest-paid employee (Lager and Loger, 1995). Later, the salary limit was increased to seven times the salary earned by an entry-level employee.

Ben and Jerry's formalized its tradition into a tripartite mission statement that reflected its goals to (a) produce high-quality products, (b) act in a socially responsible manner, and (c) ensure fiscal strength and profitability (Cohen et al., 1997). The problematic environment Ben and Jerry's faced was a result of trying to optimize all three parts of its mission. To finance the company's growth, the founders issued a public offering of stock in the company in 1984 and subsequently the third part of their mission, ensuring company profitability, was subject to increased scrutiny and priority. For example, the company faced considerable criticism from the investment community over many "socially responsible" decisions, such as a half-million dollar decision to pay dairy farmers a premium for their milk after a reduction in federal support (Lager and Loger, 1995). Many investors felt the company was not attending to the needs of the shareholders, and was 
instead too devoted to the social responsibility aspect of their mission.

When the internal tradition of Ben and Jerry's faced this problematic environment of pressure from the institutional investors, the company faced a crisis. In 1994, the company encountered lagging sales, dropping profits, stock prices down fifty percent from the previous year, and the fact that they were in the midst of constructing another ice cream factory that would more than double their production rates. Ben Cohen, one of the Ben and Jerry's founders, was the chief executive officer of what had grown into a corporation with 600 employees and sales of $\$ 140$ million. He concluded that the requirements of balancing the tri-partite mission with the realities of remaining competitive in a challenging market were beyond his managerial abilities. To lead the company through these challenges, Cohen concluded, Ben and Jerry's needed a more professional and skilled executive.

\section{"Upbuilding" dialog at Ben and Jerry's}

Following is a description of how the four "upbuilding" dialog steps of the method were used in the Ben and Jerry's crisis management situation.

(1) Approach others in an open, friendly, and respectful manner. One of the distinguishing characteristics of Ben and Jerry's tradition of linked prosperity was the degree of respect shared by all members of the organization. This resulted in an almost communal environment, reflected in a document the company published called "Our Aspirations." In it, the company said: "No one at Ben and Jerry's should feel alone or apart. When one of us needs help, we reach out for help .... We have a zest for life, a sense of humor, and we enjoy one another's company. We share the excitement of succeeding at the game of business and we'll try to have fun while we do it (Cohen et al., 1997, p. 174)."

To combat the fear that as the company grew it might lose touch with its employees, Ben and Jerry's management would have monthly meetings on the production floor for all employees to attend. These meetings were an important way the company gave a voice to employees in issues the company faced. Employees were free to talk about anything that was on their minds, such as shift scheduling or cafeteria choices, as well as to give their opinions on issues management raised, such as cutting expenses or improving benefits (Lager and Loger, 1995). The list of company aspirations also addressed this issue of giving employees a voice by adding, "To use consultative decision making and active listening: When making decisions we'll involve the people with special expertise and people likely to be affected. We'll also give those with a contrary point of view an opportunity to be heard (Cohen et al., 1997, p. 175)."

Another way Ben and Jerry worked to foster a respectful approach throughout its organization was with its progressive benefits package. Everyone in the company earned the same package, regardless of rank or tenure, which included many "standard" benefits such as health and dental coverage and life insurance, but also included unique benefits such as companyprovided child care center, a liberal vacation plan, and a contracted physical therapist to provide massages. Ben and Jerry's was also one of the first public companies in America to provide health and dental coverage and life insurance to domestic partners regardless of marital status or gender (Cohen et al., 1997). Based on the criteria of pay and benefits, opportunities for advancement, job security, pride in work and in the company, openness and fairness, and camaraderie and friendliness, the book, The Hundred Best Companies to Work for in America in 1992 and 1994 honored Ben and Jerry's for it employee relations.

(2) Frame problem as a conflict between potentially destructive environment and our tradition. When Ben Cohen, one of the company's founders, announced his decision to step down as Chief Executive Officer, he framed it as a response to the crisis created by the conflict between the potentially destructive environment and the company's tradition. He explained that he did not have the breath of experience or skills necessary to guide Ben and Jerry's into the 21st century. Cohen recognized the difficulty the company faced to maintain the social mission of linked prosperity while still administering to the fiscal mission of ensuring profitability. The environment at the time was full of potentially destructive challenges. The demand for superpremium ice cream had slowed, leading to the slowest growth rate and the first drop in profit since the company's founding. Institutional Investors questioned the ability of the company to remain profitable while still upholding 
its social mission. The value of the company's stock fell fifty percent in the one year when stock market indices were rising. Many institutional investors were insisting that the company focus more on profitability and shareholder value. By seeking a new executive officer, Ben and Jerry's hoped that a new, experienced leadership could resist the environmental pressures toward prioritization of shareholder value while balancing and still maintaining its "linked prosperity" tradition.

(3) Consider alternative solutions in context of tradition and adaptation of tradition in context of alternative solutions. When Ben and Jerry's first introduced the five-to-one salary ratio in 1985, there was lively discussion among the Board members about the impact the ratio would have on the company's tradition and environment. The proponents of the plan, which was modeled after a cooperative in Mondragon, Spain, argued that it would be a tangible representation of a tradition of fairness unlike that of companies doing "business as usual." The dissenting voices argued that the salary ratio would unduly limit the amount the company's senior management could earn, which would have a dire effect as the company grew, particularly since the company needed to depend increasingly on new equity financing for its growth. The leaders believed that the company had to grow in order to survive. The leaders believed that increased equity financing was an essential method for financing their survival required growth. Further, the leaders thought that it was essential to revise the compensation system in order to attract the type of managers needed to grow the company and increase profitability for present and future shareholders (Lager and Loger, 1995).

The company's founders entered into a dialog with the Board of Directors and the management team, as well as with all employees at an all-staff meeting. This dialog consisted of discussing the possibility of maintaining the seven-to-one salary ratio, doing away with the ratio, or finding some third way such as maintaining the ratio while exempting bonus compensations from the calculation (Mirvis, 1999; Mirvis et al., 2003). Through these dialogs, each of these options was challenged by the company's tradition just as the alternative solutions presented different challenges to the company's traditions.
As Ben and Jerry's faced the need to attract very good managers, it still had the option of maintaining its salary ratio, which by that time had been increased to seven-to-one. At the time of the announcement of his decision to step down as CEO, Cohen was earning a salary of slightly more than $\$ 130,000$, meaning the lowest paid employee would have to earn at least $\$ 19,000$. In fact, the ratio was even lower since the lowest-paid employees at the time earned about $\$ 24,000$. By paying its new CEO a competitive salary, which analysts said would be well more than $\$ 200,000$ for a company the size of Ben and Jerry's, the company would have to commit to paying its entry-level employees almost $\$ 30,000$ and adjust all other salaries accordingly. For a company with 600 employees, that cost would be exorbitant to the point that Ben and Jerry's would have to sacrifice some of its social mission just to stay in business.

The other two options, forgoing the salary ratio altogether or modifying the ratio exempting bonuses such as stock options, also were less than optimal in light of the existing tradition, and, if accepted, would require the tradition to be adapted. Forgoing the ratio would allow the company considerable financial freedom to attract the best candidate possible, at the cost of one of the fundamental elements of the organization's tradition. The last proposed solution, modifying the rules of the ratio, received less consideration since Cohen viewed such a modification of the tradition as being "duplicitous" (Mirvis, 1999; Mirvis et al, 2003).

(4) Adopting solutions that are informed by our tradition and adapting our tradition. A tradition-informed solution was adopted and the Ben and Jerry's tradition was modified. The solution Ben and Jerry's adopted was to forgo its seven-to-one salary ratio and try to attract very good managers with more competitive compensation packages. This solution was informed from within the tradition in that its goal was to seek a CEO who could lead the company to improved profitability while still maintaining its tradition and social mission of linked prosperity. In a survey he conducted at Ben and Jerry's, Phil Mirvis found that the number one predictor of how people identified with the organization was not through their individual jobs, but rather, it was through the company's social mission (Cohen et al., 1997; Mirvis, 1999). By working to solidify the company in the 
face of its challenging environment, Ben and Jerry's was also working to save the social mission, which continued to define its tradition.

While the solution was informed by tradition, the solution also adapted the tradition. By sacrificing what had long been a tangible example of the company's commitment to including employees as a vital constituent of its "linked prosperity," that tradition had to adapt. In this case, the adaptation of the tradition caused Ben and Jerry's to lose something that had been an important part of that tradition. However, the company still maintained much of what distinguished its tradition from those of companies doing "business as usual." Ben and Jerry's continued other policies. For example, it continued to give employees a progressive and comprehensive benefits package, to commit $7.5 \%$ of its pre-tax profits to charity, and to seek out and pay premiums for raw materials supplied by disadvantaged businesses. Since maintaining the company's social mission was of such definitive importance to the company's tradition, the sacrifice of the salary ratio to maintain the social mission did not erase the tradition, it adapted the tradition, and perhaps made the tradition stronger in the sense that the tradition had a voice in the decision making.

The "upbuilding" approach was effective in addressing a crisis in the development of Ben and Jerry's from an entrepreneurial endeavor into a growing, equity market financed organization. The Ben and Jerry's tradition was modified, but what the company's employees considered an important part of the tradition was saved, despite a problematic environment. In order to allow the company to continue to work toward its social mission of improving the quality of life of the local, national and international communities, as well as its economic mission of operating a profitable and fiscally sound company, the tradition had to change. Or, as Giuseppe di Lampedusa observed in The Leopard, "If we want things to stay as they are, things will have to change (di Lampedusa, 1958)."

\section{Strengths and limitations of "upbuilding" dialog method}

Strengths of the "upbuilding" method include the following: (1) the process can facilitate action-learning in ethical crisis management; (2) the process can help an organization to constructively and ethically respond to crises and problematical external pressures while helping the organization's ethical tradition learn and develop; and, (3) the friendly, respectful affect dimension of the approach can facilitate peaceful change.

Limitations include the following: (1) trusted key players are needed in such crises, but may not be available; (2) the method can be a too conservative approach to crisis management; and, (3) the approach is less applicable in crisis situations where an organization's tradition may be questionably ethical or there is inadequate consensus about what the ethical components of the tradition are; and, (4) some problematical crisis environments can actually be or can be perceived to be too powerful for an internal tradition to resist, adapt, or transform with in the sense of maintaining much of the local ethical tradition.

\section{Strengths}

(1) 'Upbuilding' can facilitate action-learning. For example, in the Ben and Jerry's case, the founders, the Board members, the workers, and the consultants all appeared to be for the most part sincere, nonadversarial, and nonlobbying. Instead, they looked for reasonable and ethical solutions to the crises that would be "neither mine nor thine." Similarly in the Dana Farber case, as part of and as a result of "upbuilding" dialogs, the President and the Chief-of-Medicine concluded that it would be good to replace themselves with people with different types of experiences as did Ben Cohen similarly conclude that Ben and Jerry's needed a different type of CEO than himself.

(2) "Upbuilding" dialog can help an organization to constructively respond to crises and problematical external pressures while helping the organization's ethical tradition learn and develop. "Upbuilding" dialog is concerned with negative deviations from shared ideals as well as reconstructive modification and reform of those tradition embedded ideals. According to Smith et al. (1990), a strong organizational tradition and ideology should not necessarily be seen as an obstacle to change and transformation. A coherent, strong tradition such as the ones at Ben 
and Jerry's and the Dana-Farber Cancer Institute can serve as a clear base from which clear alternatives can be developed and compared. In addition, a strong, highly developed, coherent tradition when it is reformed and reapplied flexibly can serve as a facilitating and legitimating bridge from one strategy/ structure configuration to another.

(3) The friendly, respectful affect dimension of the approach can facilitate peaceful change. The friendly, respectful affect dimension of the method can encourage cooperative action-learning. The Dana-Farber and Ben and Jerry's discussions appeared to proceed with relatively little bitterness and acrimony in spite of the serious crises and threats the organizations were experiencing.

\section{Limitations}

(1) Trusted key players are needed, but may not be available in such crises. If key people trying to use the approach are not trusted or are perceived as insincere, then the attempt to establish friendly, respectful affect might well fail. Use of the approach might be restricted to those situations where at least one of the key players had already established relationships of trust before the current crisis occurred. Fortunately, the leaders of Ben and Jerry's and Dana-Farber apparently were generally trusted by colleagues.

(2) "Upbuilding" can be a too conservative approach to crisis management. The method focuses on transformation from within an ethical tradition. However, the key problem might be a problematical internal tradition rather than a problematical environment. That is, the polarity of the situation may be reversed. Instead of the situation of a problematical environment poisoning a good internal tradition, the reverse might be the case: the external crowd could be enlightened and the internal tradition might be problematical. For example, in another research hospital, there might be genuinely little concern in the organization's tradition for compassionate patient care relative to advanced research. It is possible that some organization traditions have biases that are entangled with and support behaviors that need to be pressured to change by an external, national level movements such as was the case with some self centered corporate management traditions that needed to be pressured by investor capitalists to improve corporate governance and pay some attention to majority and minority shareholder concerns (Useem, 1996).

(3) This approach is less applicable in situations where a tradition may be questionably ethical or there is inadequate consensus about what the ethical components of the tradition are. That is, not all organizations do or can use this method.

For example, Citigroup has agreed to pay a \$400 million fine for its investment banking activities that facilitated earning misrepresentation in the high technology and telecommunications industries and for misleading investors with its falsely positive research reports on these industries without admitting guilt. Citigroup has also agreed to pay $\$ 2.7$ billion dollars in a settlement with shareholders of WorldCom for those similar investment banking and misleading research activities, again without admitting guilt (Morgenson, 2002; Nielsen, 2005; O'Brien and Thomas, 2004; Sapsford, 2004; The Economist, 2003).

During the five year time period of these investment banking and research reporting activities, the CEO of Citigroup, Sanford Weill received \$1 billion in compensation. Since then, the private banking unit of Citigroup has been barred by the Japanese government from operating in Japan for illegal and unethical activities and the UK bond trading unit of Citigroup is under investigation in England for manipulation of the London bond market.

Several executives have been fired for these activities. Several have been given very generous severance packages. Citigroup has agreed to pay legal fees that fired managers may subsequently face as well as lost arbitration cases for the fired managers, again without admitting any guilt.

To date, there does not appear to be any use of a Kierkegaardian "Upbuilding" method of examining and including the ethical, or lack thereof, tradition of Citigroup in addressing these several crises. Instead, the Citigroup method seems to be: if we get caught for unethical and illegal practices, negotiate a settlement that includes large fines and penalties, admit no guilt, fire managers, and pay the fired managers generous severance packages and legal fees, and move on. We wonder whether the fired managers also agreed not to testify against the highest level 
managers and corporate officers of Citigroup in exchange for their severance packages, legal fees, and for Citigroup agreeing to pay potential arbitration fines instead of the fired managers.

And as referred to in the introduction to this article, even an organization such as Johnson and Johnson that established such a good reputation for responding to the externally poisoned Tylenol capsules crisis based on its internal ethical tradition, seems to have failed to do so in a different crisis. That is, it appears that Johnson and Johnson systematically suppressed information about the liver damaging effects of its Tylenol medicine for over twenty years (Bates and Hall, 1994; Grady, 1997; Tennant, 2004). Many more people may have died from Tylenol caused liver damage than the cyanide poisoning.

(4) Some problematical crisis environments can actually be or can be perceived to be too powerful for an internal tradition to resist, adapt, or transform with in the sense of maintaining much of the local ethical tradition (Nielsen, 2003). If the key leaders and members of an organizational community and tradition believe that external forces are too powerful to resist and/or adapt and transform with, they may both be correct in that evaluation and/or may give up without trying to preserve, adapt, and address crises from within their local traditions. For example, the economic survival pressures facing Ben and Jerrry's subsequent to the 1994 crisis resulted in the company being acquired by the multinational company Unilever in 2000 (Fiano, 2000; Hechinger and Pereira, 2000; Mirvis et al., 2003; Steiker and Golden, 2000). It is not clear how much of the Ben and Jerry's tradition can survive as part of such a much larger multinational corporation. For example, within Unilever, there does not appear to be much left of the Quaker tradition of the early 1800s Lever Brothers family business (Windsor, 1980).

\section{Conclusion}

The "upbuilding" method is an extension and adaptation of the Kierkegaardian "upbuilding" process to organizational crisis management. Much of management and organizational crisis management scholarship is implicitly framed within the classical and neo-classical framework of organizations having to adjust and respond to external markets and environments.

The "upbuilding" perspective and approach reframes the crisis. Instead of the crisis being defined as how to change an organization so that it can more prosperously adjust to an external environment, the problem is in a sense reversed. Tradition embedded value considerations are explicitly introduced. The reframed crisis management problem then becomes one of how to simultaneously maintain, stimulate, and enable the organization's ethical tradition while resisting and withstanding problematical crisis environments while also considering when and how the tradition needs to bend and change in the context of the dialog with and about the crisis. We need not always have to change in response to problematical environments, we can also protect, reform, and enable our ethical traditions in the face of and even the opportunity of crises. We can both better respond to crises and deepen and strengthen our ethical organizational traditions. As Kierkegaard explained, "The principle of association, by strengthening the individual, enervates him. It is only after ... an ethical outlook, in face of the whole world, that there can be any suggestion of really joining together."

\section{References}

Argyris, C. and D. A. Schon: 1974, Theory in Practice, (Jossey-Bass, San Francisco).

Argyris, C. and D. A. Schon: 1988, Reciprocal Integrity: Creating Conditions that Encourage Personal and Organizational integrity, in S. Srivastva and Associates (ed.), Executive Integrity: The Search for High Human Values in Organizational Life. Jossey-Bass Publishers, San Francisco, pp. 197-222.

Argyris, C., R. Putnam, and S. D. Mc Lain: 1985, Action Science, (Jossey-Bass Publishers, San Francisco).

Argyris, D.: 1985, 'The Ethnographic Approach to Intervention and Fundamental Change', in C. Argyris, R. Putnam, and D. M. Smith (eds.), Action Science (Jossey-Bass Publishers, San Francisco), pp. 158-189.

Aristotle: 1955, Ethics (Penguin Classics, New York).

Audia, P. G., E. A. Locke and K. G. Smith: 2000, 'The Paradox of Success: An Archival and a Laboratory Study of Strategic Persistence Following Radical Environmental Change', Academy of Management Journal 43(5), 837-853. 
Bates, S. and C. W. Hall: 1994, 'Tylenol Verdict puts Spotlight on Drug Labels', Washington Post, October 22, p. A1.

Bateson, G.: 1972, Steps to an Ecology of Mind (Ballantine Books, New York).

Bernstein, R. J.: 1971, Praxis and Action (University of Pennsylvania Press, Philadelphia).

Buono, A. F. and J. L. Bowditch: 1989, The Human Side of Mergers and Acquisitions (Jossey-Bass, San Francisco).

Carlzon, J.: 1987, Moments of Truth (Ballinger Publishing Company, Cambridge, MA).

Chanin, M. N. and H. J. Shapiro: 1985, 'Dialectical Inquiry in Strategic Planning: Extending the Boundaries', Academy of Management Review 10(4): 663-675.

Chappell, T.: 1993, 'The Soul of a Business: Managing for Profit and the Common Good', (Bantam Books, NY).

Churchman, C. W.: 1966, Hegelian Inquiring Systems. Working paper No. 49, University of California, Berkeley, Space Sciences Laboratory, Social Sciences Project.

Churchman, C. W.: 1968, The Systems Approach (Dell Publishing, New York).

Churchman, C. W.: 1971, The Design of Inquiring Systems: Basic Concepts of Systems and Organization (Basic Books, New York).

Cohen, B. G. and M. Meredith: 1997, Ben and Jerry's Double-Dip: How to Run a Values-led Business and Make Money Too. Fireside.

Collins, J. C. and J. I. Porras: 1994, Built to Last: Successful Habits of Visionary Companies (Harper Collins, New York).

Cosier, R. A.: 1981a, 'Dialectical Inquiry in Strategic Planning: A Case of Premature Acceptance?' Academy of Management Review, 6(4), 643-648.

Cosier, R. A.: 1981b, 'Further Thoughts on Dialectical Inquiry: A Rejoinder to Mitroff and Mason', Academy of Management Review 6(4): 653-654.

Czarniawska, B. 1997, Narrating the Organization: Drama of Institutional Identity (The University of Chicago Press, Chicago).

Deephouse, D. L.: 1996, 'Does Isomorphism legitimate?' Academy of Management Journal 39, 1024-1039.

Derrida, J.: 1977, Limited inc. (Northwestern University Press, Evanston, IL). See especially, Afterword: Toward an Ethic of Discussion, pp. 111-154.

Derrida, J.: 1981, 'Three Questions to Hans-Georg Gadamer. Interpreting Signatures (Nietzsche/Heidegger): Two Questions', in D. P. Michelfelder and R. E. Palmer: 1989, Dialogue and Deconstruction: The Gadamer-Derrida Encounter (State University of New York Press, Albany). di Lampedusa, G.: 1958, Il Gattopardo. Milano, Italy (1961). The Leopard (Signet, New York).

DiMaggfio, P. J. and W. W. Powell: 1983, 'The Iron Cage Revisited: Institutional Isomorphism and Collective Rationality in Organizational Fields', American Sociological Review 48, 147-160.

Ewing, D. W.: 1989, Justice on the Job. Harvard Business School Press, Boston.

Feldman, S. P.: 2002, Memory as a Moral Decision: The Role of Ethics in Organizational Culture. (Transaction Publishers, New Brunswick).

Fiano, A.: 2000, Unilever's Hefty Tab for Ben and Jerry and Slim-Fast, Barron's, April 17, p. MW13.

Fiol, C. M.: 2002, 'Capitalizing on Paradox: The Role of Language in Transforming Organizational Identities', Organization Science 13(6), 653-666.

Fleischacker, S.: 1994, The Ethics of Culture (Cornell University Press, Ithaca).

Gadamer, H.-G.: 1960, 1989, Truth and Method, (Crossroad, New York).

Gilmour, D.: 1988, The Last Leopard: A Life of Giuseppe Tomasi di Lampedusa Pantheon, New York.

Grady, D.: 1997, 'Tylenol Overdoes Linked to Acute Failure of Liver', New York Times, October 16, Section A, p. 18 .

Haverman, H. A.: 1992, 'Between a Rock and a Hard Place: Organizational Change and Performance Under Conditions of Fundamental Environmental Transformation', Administrative Science Quarterly 37: $48-75$.

Hechinger, J. and J. Pereira: 2000, 'Sympathizers Scramble to Rid Ben and Jerry's of Two Unwanted Suitors', The Wall Street Journal, February 4, p. 1, A20.

Hill, Charles W. L. and F. T. Rothaermel: 2003, 'The Performance of Incumbent Firms in the Face of Radical Technological Innovation', The Academy of Management Review 28(2), 257-274.

Hooper, L. and M. W. Miller: 1992, 'IBM Shares Fall $11 \%$ as Firm Says It Will Cut 25,000 Jobs and May Trim Dividend', Wall Street Journal, December 16, 1992, 3.

Kearney Richard: 1998, 'The wake of imagination', University of Minnesota Press, Minneapolis.

Kierkegaard, S.: 1843, 1944, Either/Or (David F. and Lillian Swenson, Walter Lowrie, Translators). (Princeton University Press, Princeton).

Kierkegaard, S.: 1845, 1967, Stages on Life's Way (Walter Lowrie, Translator). Schocken Books, New York.

Kierkegaard, S.: 1846a, 1968 Concluding Unscientific Postscript to the Philosophical Fragments (David F. Swenson, Translator). Princeton University Press, Princeton. 
Kierkegaard, S.: 1846b, 1962. The Present Age (Alexander Dru, Translator). Harper Torchbook, New York.

Kierkegaard, S.: 1847a, 1946, Works of Love (David F. Swenson, Trans.). Princeton University Press, Princeton.

Kierkegaard, S.: 1847b, 1948, Purity of Heart (D. Steere, Trans.) Harper and Row, NY.

Knox, R. A.: 1995a, Overdoses Still Weigh Heavy at Dana-Farber More than Year After Tragedy, Cancer Institute Works to Balance Research Mission, Crucial Details of Patient Care. Boston Globe, December 26, p. 1, 6 .

Knox, R. A.: 1995b, New Dana-Farber Head Vows "Never again." Boston Globe, September, 16, p. $1,9$.

Knox, R. A.: 1995c, President of Troubled Dana-Farber Steps Down. Boston Globe, September 13, p. 1, 7.

Knox, R. A.: 1995d, Dana-Farber Head Quits 2nd Post, Vows Changes. Boston Globe, p. 1, 11.

Knox, R. A.: 1995e, Dana-Farber on Probation: Agency Downgrades Accreditation. Boston Globe, April 15, p. 17.

Knox, R. A.: 1995f, Doctor's Orders Killed Cancer Patient: Dana-Farber Admits Drug Overdose Caused Death of Globe Columnist, Damage to Second Woman. March 23, p. 1, 6.

Knox, R. A. and K. Blanton: 1995, Overdose Cloud Dana-Farber Bonds. Boston Globe, March 24, p. 77.

Kong, D.: 1995a, State Faults Dana-Farber. Boston Globe, March 24, pp. 1, 12.

Kong, D.: 1995b, Safeguards Failed at Dana-Farber. Boston Globe, March 25, pp. 1, 8.

Kostova, T. and S. Zaheer: 1999, 'Organizational Legitimacy Under Conditions of Complexity', Academy of Management Review 24(1), 64-81.

Lager, F. and Loger, F. C.: 1995, Ben and Jerry's: The Inside Scoop: How Two Guys Build A Business With a Social Conscience and A Sense of Humor. (Crown Publishing, New York).

Lawrence, F.: 1984, 'Language as horizon', in F. Lawrence (ed.), The Beginning and The Beyond (The Scholars Press, Chico, CA).

Lewin, K.: 1951, Field Theory in Social Science (Harper, New York).

Lowrie, W.: 1942, 1970, A Short Life of Kierkegaard (Princeton University Press, Princeton).

Mirvis, P.: 1999, Electronic Mail Conversation, October 25.

Mirvis, P. H., G. R. Karen Ayas: 2003, To the Desert and Back (Jossey-Bass, San Francisco).

Mitroff, I. I. and Mason, R. O.: 1981, 'The Metaphysics of Policy and Planning: A Reply to Cosier', Academy of Management Review 6(4), 649-651.
Mitroff, I., T. Pauchant and P. Shrivastava: 1988, 'Conceptual and Empirical Issues in the Development of a General Theory of Crisis Management', Technological Forecasting and Social Change 33, 83-107.

Morgenson, G.: 2002, 'Analyze This: What Those Analysts said in Private', New York Times, September 15, section 3, p. 1.

Nielsen, R. P.: 2005, 'Systematic Corruption in Financial Services, Types of Capitalism, and Ethics Intervention Methods', Business and Professional Ethics Journal 23(1\&2), 1-31.

Nielsen, R. P.: 2004, 'Ethics and Organizational Theory: Varieties and Dynamics of Constrained Optimization in Different Types of Capitalism', in H. Tsoukas and C. Knudsen (eds.), The Oxford Handbook of Organizational Theory: Meta-Theoretical Perspectives (Oxford University Press, London), pp. 476-501.

Nielsen, R. P.: 2003, 'Corruption Networks and Implications For Ethical Corruption Reform', Journal of Business Ethics 42, 125-149.

Nielsen, R. P.: 1998, 'Can Ethical Character be Stimulated and Enabled?' Business Ethics Quarterly 8(3), 581-604.

Nielsen, R. P.: 1996a, The Politics of Ethics: Methods For Acting, Learning, and Sometimes Fighting, With Others in Addressing Ethics Problems in Organizational Life. (The Ruffin Series in Business Ethics, Oxford University Press, New York).

Nielsen, R. P.: 1996b, 'Varieties of Dialectic Change Processes', Journal of Management Inquiry 5(3), 276-292.

Nielsen: 1989, 'Changing Unethical Organizational Behavior' Academy of Management Executive 3(2), 123-130.

Nielsen, R. P.: 1993, 'Woolman's “I Am We" Tripleloop, Action-Learning: Origin and Application in Organization ethics', Journal of Applied Behavioral Science 29(1) 117-138.

Nielsen, R. P.: 1988, Personal Conversation with Douglas Steere.

O’Brien, T. L. and T. Landon: 2004, 'It's Cleanup Time at Citi: A New C.E.O. Aims to Overhaul the Superbank's Culture', New York Times, Nov. 7, 2004, section 3, pp. 1-7.

Oliver, C.: 1991, 'Strategic Responses to Institutional Processes', Academy of Management Review, 16, 145-179.

Oxford English Dictionary: 1971, (Oxford University Press, New York).

Pearson, C. M. and J. A. Clair: 1998, 'Rethinking Crisis Management', Academy of Management Review, 23: 5976.

Pearson, C. M., J. A. Clair, S. Kovoor-Misra and I. I. Mitroff: 1997, 'Managing the Unthinkable'. Organizational Dynamics, Autumn, 51-64. 
Pfeiffer, S.: 1999, Court Protects Anonymity of Globe Sources in Dana-Farber Case. The Boston Globe, February 27, p. B4.

Rogers, B.: 1986, The IBM way (Harper and Row, New York).

Sapsford, J.: 2004, Citigrop's Weill Received Bonus of \$29 Million in Cash for 2003, Wall Street Journal, March 17, C3.

Schrivastava, P.: 1993, 'Crisis Theory/Practice: Towards a Sustainable Future', Industrial and Environmental Crisis Quarterly 7(1), 23-42.

Schweiger, D. M., W. R., Sandberg, and J. W. Ragan: 1986, 'Group Approaches for Improving Strategic Decision Making: A Comparative Analysis of Dialectical Inquiry, Devil's Advocacy, and Consensus', Academy of Management Journal, 29(1), 51-71.

Schweiger, D. M. and W. R. Sandberg: 1989, 'The Utilization of Individual Capabilities in Group Approaches to Strategic Decision Making', Strategic Management Journal 10, 31-43.

Schweiger, D. M., W. R. Sandberg, and P. L. Rechner: 1989, 'Experiential Effects of Dialectical Inquiry, Devil's Advocacy, and Consensus Approaches to Strategic Decision Making', Academy of Management Journal 32(4), 745-722.

Senge, P.: 1990, The Fifth Discipline (Doubleday, New York).

Smith, C., J. Child, and M. Rowlinson: 1990, Reshaping Work: The Cadbury Experience (Cambridge University Press, Cambridge).
Smith, R., C. Susanne and S. Deborah: 2003, Wall Street Firms to Pay $\$ 1.4$ Billion to End Inquiry, Wall Street Journal, April 29, p. 1, 6.

Steere, D.: 1938, Translator's introduction to Soren Kierkegaard's Purity of Heart Harper and Row, New York.

Steere, D.: 1949, Introduction to Soren Kierkegaard's Works of Love (Princeton University Press, Princeton).

Steere, D.: 1957, Work and contemplation (Harper \& Brothers, New York).

Steiker, J. and Michael G.: 2000, Insiders Tell How Social Investors Tried to (but couldn't) Buy Ben and Jerry's, Business Ethics, May-June, p. 7.

Tennant, F.: 2004, 'The Tylenol Toxicity Issue', Intractable Pain News, February 27, pp. 1-2.

The Economist: 2003, 'The Wall Street Settlement: Unclean Slate', January 4, p. 59.

Weick, K. E.: 1979, The social psychology of organizing (Random House, New York).

Windsor, D. B.: 1980, The Quaker Enterprise: Friends in Business (Frederick Muller Limited, London).

Richard P. Nielsen Ron Dufresne Department of Organization studies, Boston College, 214 Fulton Hall, Chestnut Hill, Boston, U.S.A E-mail: richard.nielson@bc.edu 